Article

\title{
Improvement of a Genetic Transformation System and Preliminary Study on the Function of $L p A B C B 21$ and LPPILS7 Based on Somatic Embryogenesis in Lilium pumilum DC. Fisch
}

\author{
Shengli Song ${ }^{1}{ }^{\circledR}$, Rui Yan ${ }^{1}$, Chunxia Wang ${ }^{1}$, Jinxia Wang ${ }^{1}$ and Hongmei Sun ${ }^{1,2, *}$ \\ 1 Key Laboratory of Protected Horticulture of Education Ministry and Liaoning Province, \\ College of Horticulture, Shenyang Agricultural University, Shenyang 110866, China; ssl_syau@163.com (S.S.); \\ yanrui2020@sina.cn (R.Y.); $2004500043 @$ syau.edu.cn (C.W.); wangjinxia74@163.com (J.W.) \\ 2 National and Local Joint Engineering Research Center of Northern Horticultural Facilities Design and \\ Application Technology, Shenyang 110866, China \\ * Correspondence: sunhm@syau.edu.cn; Tel.: +86-24-8848-7143
}

Received: 12 August 2020; Accepted: 14 September 2020; Published: 16 September 2020

\begin{abstract}
Auxin transport mediates the asymmetric distribution of auxin that determines the fate of cell development. Agrobacterium-mediated genetic transformation is an important technical means to study gene function. Our previous study showed that the expression levels of $L p A B C B 21$ and LPPILS7 are significantly up-regulated in the somatic embryogenesis (SE) of Lilium pumilum DC. Fisch. (L. pumilum), but the functions of both genes remain unclear. Here, the genetic transformation technology previously developed by our team based on the L. pumilum system was improved, and the genetic transformation efficiency increased by $5.7-13.0 \%$. Use of overexpression and CRISPR/Cas9 technology produced three overexpression and seven mutant lines of LpABCB21, and seven overexpression and six mutant lines of LPPILS7. Analysis of the differences in somatic embryo induction of transgenic lines confirmed that $L P A B C B 21$ regulates the early formation of the somatic embryo; however, excessive expression level of $\angle P A B C B 21$ inhibits somatic embryo induction efficiency. LPPILS7 mainly regulates somatic embryo induction efficiency. This study provides a more efficient method of genetic transformation of L. pumilum. LpABCB21 and LPPILS7 are confirmed to have important regulatory roles in L. pumilum SE thus laying the foundation for subsequent studies of the molecular mechanism of Lilium SE.
\end{abstract}

Keywords: Lilium pumilum DC. Fisch.; somatic embryogenesis; auxin transport; genetic transformation; CRISPR/Cas9

\section{Introduction}

Auxin plays a critical role in plant development by controlling cell expansion, polarity, and organ patterning [1]. Auxin is mainly synthesized in expanding leaves along with shoot apical meristem and is transported to various parts of the plant [2] by polar auxin transport (PAT) [3]. Three crucial plasma membrane (PM) auxin transporters are involved in the PAT system, PIN-FORMED (PIN) auxin efflux facilitators [4], AUXIN1/LIKE AUX1 (AUX1/LAX) influx carriers [5], and ATP-binding cassette $(\mathrm{ABC})$ transporter B family (ABCB) efflux/influx transporters [6]. PIN-LIKES (PILS) located at the endoplasmic reticulum (ER) has also been shown to be involved in auxin transport $[7,8]$.

The $\mathrm{ABCB}$ subfamily is the second largest $\mathrm{ABC}$ protein subfamily in plants with 10, 18, 21, and 22 ABCB members in Physcomitrella patens, Selaginella moellendorfii, Arabidopsis thaliana, and Oryza sativa, respectively [9]. Some members of the ABCB subfamily have been confirmed to be 
involved in auxin transport; $\mathrm{ABCB} 1, \mathrm{ABCB} 4, \mathrm{ABCB} 14, \mathrm{ABCB} 19$, and $\mathrm{ABCB} 21$ are the most intensively studied members $[9,10]$. ABCBs can regulate auxin transport over long and short distances [11] and plant ABCBs are selective to auxin substrates [12]. For example, ABCB19 [13] and ABCB21 [14] have higher transport activity for IAA (indole-3-acetic acid) than that for NAA (1-naphthaleneacetic acid). ABCB1 [15], ABCB4 [16], and ABCB19 [17] can bind 2,4-D (2,4-dichlorophenoxyacetic acid); however, ABCB4 has a higher affinity for 2,4-D [16]. The AUX1/LAX auxin transport family mainly regulates the influx of auxin $[5,18]$. However, two members of the ABCB subfamily have different characteristics including $\mathrm{ABCB} 4$ and $\mathrm{ABCB} 21$, which are auxin concentration-dependent influx/efflux transporter that mediate the influx activity when the cytoplasmic auxin concentration is low and efflux activity when the auxin concentration is high $[14,16]$.

The structure of PILS proteins (PILS1-PILS7) is similar to PIN proteins, although the former constitute an independently evolved protein family [19]. PILS and PIN proteins have only approximately $10-18 \%$ sequences similarity; however, both protein families contain auxin transport domains and are involved in intracellular auxin accumulation [7]. PILS protein family may be more ancient and conserved even in unicellular algae $[20,21]$. PILS proteins regulate intracellular auxin accumulation at the ER and consequent auxin availability for nuclear auxin signaling [7,8,22]. Additionally, non-canonical PIN proteins, such as AtPIN5/6/8, are also located at the ER and participate in intracellular auxin transport $[20,23]$. The function of PILS proteins in development is unclear, and it is currently believed that PILS proteins can limit the rate of auxin signal transduction and response to external stimuli, such as light and temperature, to regulate auxin-dependent development $[8,22]$. For example, the light signaling pathway can directly regulate the activity of PILS thus regulating phototropic growth [22]. High temperature can inhibit the expression of PILS6 and increase auxin signal thus promoting organ development [8]. A recent study has demonstrated that PILS proteins are involved in the interaction between brassinosteroid and auxin to regulate plant development [24].

Genetic transformation is an important technical means to study gene function. Agrobacterium-mediated transformation is a plant transformation method that employs an efficient and low-cost system that has been widely used for stable gene transfer [25]. In this process, the expression of a tumor-inducing (Ti) plasmid of Agrobacterium is necessary for T-DNA (transfer DNA) transfer into the host cells to integrate T-DNA into the host genome [26]; the virulence (vir) gene of the TI plasmid determines the transformation ability of Agrobacterium [27-29]. Activation of the vir gene requires signals from the host plants, including phenolic derivatives, acidic $\mathrm{pH}$, monosaccharides, and low $\mathrm{PO}_{4}$ [27-31]. Phenols are the major signal components in plants, and phenolic signal can be enhanced by certain sugars, low $\mathrm{pH}$, and low $\mathrm{PO}_{4}[28,32]$. Monocotyledons are generally considered to be insensitive to Agrobacterium infection and transformation due to lack of wound response [33] and deficiency in phenolic derivatives [32]. Lilium has been one of the recalcitrant monocotyledon species for Agrobacterium-mediated transformation until transgenic lily was generated for the first time [34]. Since then, numerous studies on genetic transformation of Lilium and several Lilium varieties have successfully obtained transgenic plants, such as Lilium $\times$ formolongi [35], Lilium tenuifolium oriental $\times$ trumpet "Robina" [36], Lilium oriental "Sorbonne" [37], and Lilium cv "Manissa" [38]. However, due to the strong genotype dependence, low efficiency of stable transformation, poor genetic stability, and difficult regeneration after transformation, this technique is still unable to meet the current requirements of Lilium [39]. In 2019, the genetic transformation system of Lilium pumilum DC. Fisch. (L. pumilum) was successfully established in our study [39]; however, the system is not perfect because it needs a long transformation cycle and its transformation efficiency is relatively lower than that of model plants.

At present, the regulatory role of auxin transport in somatic embryogenesis (SE) remains unclear. Our previous results demonstrated that the expression levels of LpABCB21 and LpPILS7 auxin transporters are significantly up-regulated in SE and may play an important regulatory role in L. pumilum SE [40]. Moreover, the genetic transformation system of L. pumilum developed previously by our team [39] is improved by optimization of the $\mathrm{pH}$ of RC (re-suspension solution and co-culture 
medium), and the germination conditions of resistant calli. In this study, the genetic transformation efficiency is increased after the improvements, and important regulatory roles of $L p A B C B 21$ and LPPILS7 in L. pumilum SE are confirmed.

\section{Results}

\subsection{Construction of Expression Vectors}

Complete CDSs (coding sequences) of LpABCB21 (4086 base pairs (bp)) and LpPILS7 (1461 bp) were inserted into the pRI101-ON vector by double enzymes digestion, and the generated vectors were named OE-LPABCB21 and OE-LPPILS7, respectively (Figure 1A). The sequences information is listed in Supplementary File.

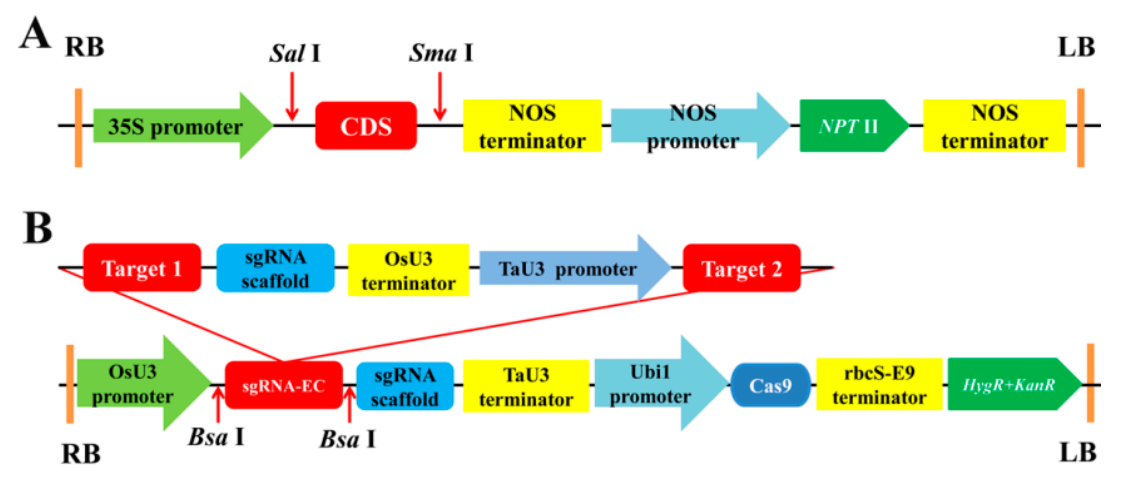

Figure 1. Schematic diagram of the recombinant vector. (A) schematic diagram of recombinant vectors OE-L $p A B C B 21$ and OE-LpPILS7. (B) schematic diagram of recombinant vectors KO-LPABCB21 and KO-LPPILS7. RB and LB are the right and left borders of the recombinant vector, respectively; NPT II is a selection marker gene for overexpression lines. $H y g R$ and $K a n R$ are selection marker genes for mutant lines. sgRNA-EC is a dual sgRNA expression cassette.

A 20 bp sgRNA (small-guide RNA) was selected in the conserved domain of the CDS. The sgRNA sites in LpABCB21 and LpPILS7 are shown in Figure 2. Dual sgRNA expression cassette was successfully constructed by overlapping PCR (polymerase chain reaction). Dual sgRNA expression cassette was inserted into the $\mathrm{pG} 3 \mathrm{H}-\mathrm{U} 3 \mathrm{Ub}$ vector using single enzyme digestion, and the corresponding vectors were named KO-LpABCB21 and KO-LpPILS7 (Figure 1B).

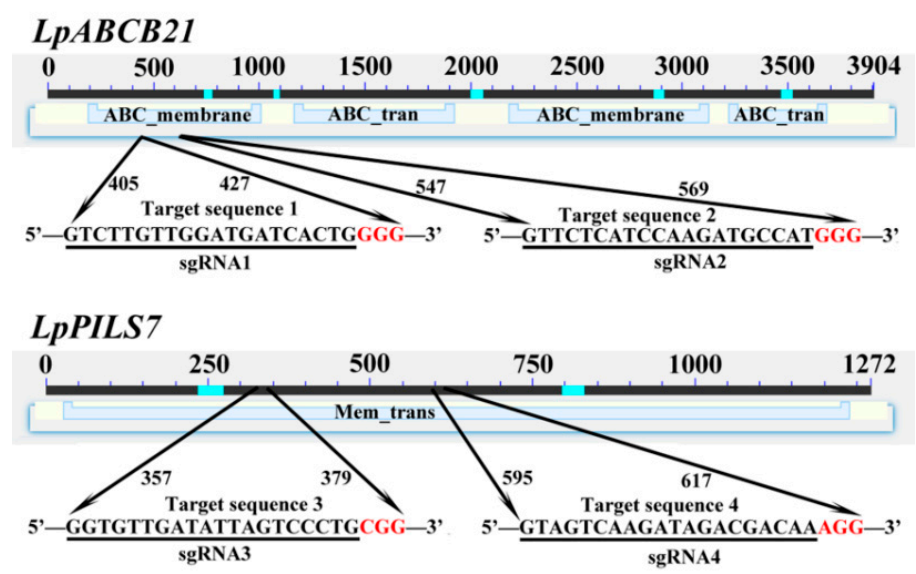

Figure 2. Selection of sgRNA for $L p A B C B 21$ and LpPILS7 gene editing. The conserved domains and their locations are labeled. The cyan lines correspond to compositionally biased regions and were not used for domain database search. The red letters correspond to the NGG domains. 


\subsection{Comparison of Genetic Transformation Systems before and after the Improvement}

After two rounds of antibiotic screening, the transformed calli were cultured in somatic embryo induction medium for 30 days. The growth of resistant calli is shown in Figure 3. The results indicate that a higher number of resistant calli masses were generated by the RC5.0 treatment (Re-suspension II and Co-cultivation II) (E-H) than that was generated by the RC5.8 (Re-suspension I and Co-cultivation I) (A-D), and all resistant calli masses had a larger volume and a higher number of clusters.
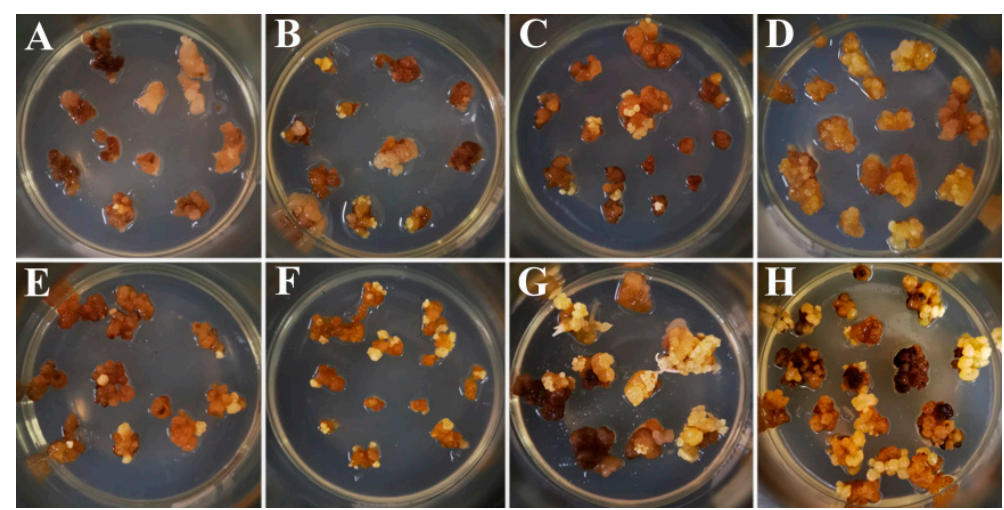

Figure 3. The growth of resistant calli at various $\mathrm{pH}$ of $\mathrm{RC}$ (re-suspension solution and co-cultivation medium). (A-D), resistant calli obtained in RC with $\mathrm{pH}$ 5.8. (E-H), resistant calli obtained in RC with $\mathrm{pH}$ 5.0. A and $\mathrm{E}$, the results of OE-LPABCB21 infection. $\mathrm{B}$ and $\mathrm{F}$, the results of OE-LpPILS7 infection. $\mathrm{C}$ and $\mathrm{G}$, the results of KO-LpABCB21 infection. D and $\mathrm{H}$, the results of KO-LpPILS7 infection.

As shown in Table 1, the number of resistant calli masses obtained by the RC5.0 treatment increased by approximately $2-3$-fold.

Table 1. The number of resistant calli under various transformation conditions.

\begin{tabular}{ccccc}
\hline Treatment & OE-LpABCB21 & OE-LpPILS7 & KO-LpABCB21 & KO-LpPILS7 \\
\hline RC5.8 & $13 / 205(6.34 \%)$ & $21 / 247(8.50 \%)$ & $35 / 243(14.40 \%)$ & $31 / 225(13.78 \%)$ \\
RC5.0 & $42 / 213(19.72 \%)$ & $46 / 231(19.91 \%)$ & $59 / 223(26.46 \%)$ & $67 / 246(27.24 \%)$ \\
\hline
\end{tabular}

Note: Re-suspended solution and co-culture medium had pH 5.8 (RC5.8) or 5.0 (RC5.0). m/n (\%), m represents the number of newly formed calli, $\mathrm{n}$ represents the number of inoculated calli, and $\%$ represents the percentage of newly formed calli in the inoculated calli.

As shown in Figure 4, the resistant calli obtained by treatment with RC5.8 and RC5.0 were subcultured for 30 days under Germination I (A-D) and Germination II conditions (E-H), respectively. Thirty-seven OE-LpABCB21 resistant plants were obtained, including 32 plants under Germination II condition (D) and five plants under Germination I condition (A). Thirty-seven OE-LpPILS7 resistant plants were obtained, including 30 plants under Germination II condition (F) and seven plants under Germination I condition (B). Fifty-six KO-LPABCB21 resistant plants were obtained, including 41 plants under Germination II condition $(\mathrm{G})$ and 15 plants under Germination I condition $(\mathrm{C})$, and 63 KO-LpPILS7 resistant plants, including 52 plants under Germination II condition (H) and 11 plants under Germination I condition (D). 

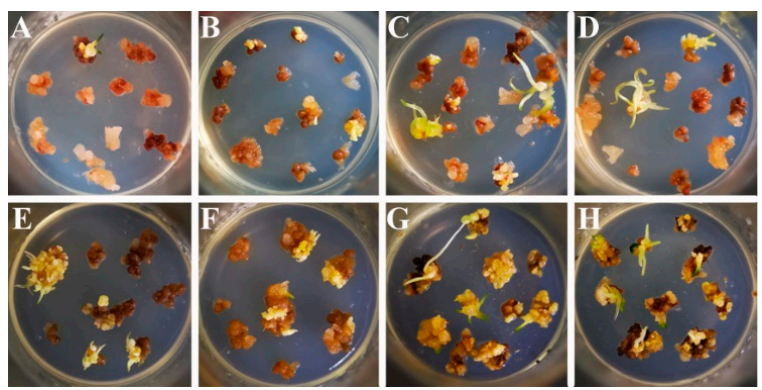

Figure 4. Resistant calli germination. (A) and (E), OE-LpABCB21; (B) and (F), OE-LpABCB7; (C) and (G), KO-LpABCB21; (D) and (H), KO-LpPILS7. (A-D), Germination I condition; (E-H), Germination II condition.

\subsection{Identification of Transgenic Plants}

As shown in Figure 5, the transgenic plants were identified by PCR. The NPTII gene fragment (817 bp) and the specific fragment between the vector and the target gene (1105 bp/1004 bp) were successfully cloned, and the positive plants were identified. After verification, 3 OE-LpABCB21 positive lines (L2, L11, and L12) and 7 OE-LpPILS7 positive lines (L5, L13, L17, L25, L27, L30, and L32) were obtained. All lines except L32 were obtained after the improvement.
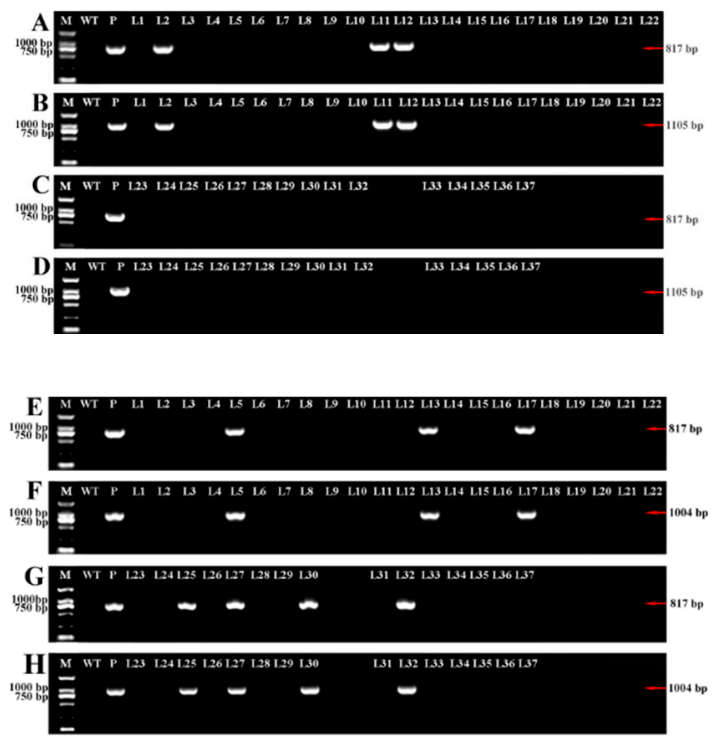

Figure 5. PCR (polymerase chain reaction) identification of OE-LpABCB21 (A-D) and OE-LpPILS7 $(\mathbf{E}-\mathbf{H})$ positive lines. $(\mathbf{A}, \mathbf{C}, \mathbf{E})$ and $(\mathbf{G})$ are the cloning results of NPTII gene $(817 \mathrm{bp}) ;(\mathbf{B})$ and $(\mathbf{D})$ are the cloning results obtained using the primers against the 35S promoter and LpABCB21 (1105 bp); (F) and (H) are the cloning results obtained using the primers against the 35 S promoter and LpPILS7 (1004 bp). L33-L37 in (C,D) and L31-L37 in $(\mathbf{G}, \mathbf{H})$ are obtained before the improvement. The other lines are obtained after the improvement. M, 2 kb DNA marker. WT, wild-type plant. P, vector plasmid control.

As shown in Figure 6, the specific fragment (421 bp) between the vector and the sgRNA expression cassette was successfully cloned and the positive plants were identified. After verification, $24 \mathrm{KO}-L p A B C B 21$ positive plants were obtained; however, five plants were obtained before the improvement. $24 \mathrm{KO}$-LpPILS7 positive plants were obtained; however, only 5 plants were obtained before the improvement. 


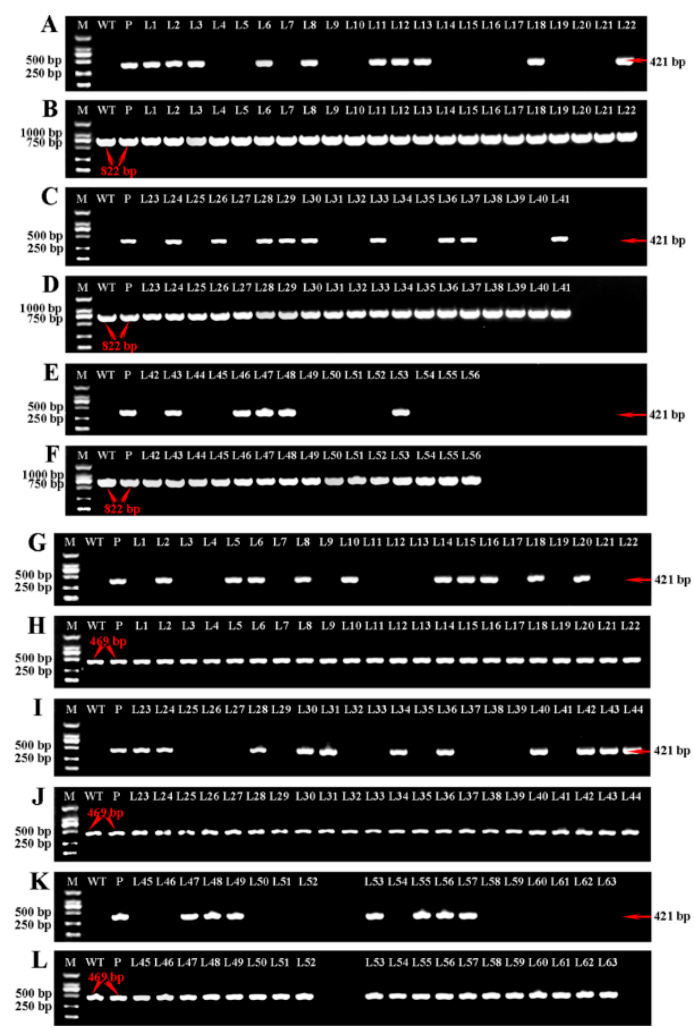

Figure 6. PCR identification of KO-LpABCB21 (A-F) and KO-LpPILS7 (G-L) positive plants. (A,C,E,G,I) and $(\mathbf{K})$ are the cloning results obtained using the primers against the OsU3 promoter and sgRNA expression cassette (421 bp). (B,D) and (F) are the cloning results of the fragments on LpABCB21 containing dual sgRNA $(822 \mathrm{bp}) .(\mathbf{H}, \mathbf{J})$ and $(\mathbf{L})$ are the cloning results of the fragments on LpPILS7 containing dual sgRNA (469 bp). L42-L56 in (E,F) and L53-L63 in (K,L) are obtained before the improvement. The other lines are obtained after the improvement. M, 2 kb DNA marker. WT, wild-type plant. P, vector plasmid control.

To identify the mutation modes of the mutant lines, the cloned PCR fragments from KO-LpABCB21 and KO-LPPILS7 positive plants were purified and sequenced; the mutation modes are shown in Figure 7. Mutations occurred in 7 of the $24 \mathrm{KO}-L p A B C B 21$ positive plants, and no mutations occurred in line L29 at the sgRNA1 site. Mutations occurred in six of the $28 \mathrm{KO}-L p P I L S 7$ positive plants, and heterozygous mutations occurred in lines L10 and L28 at the sgRNA3 site.
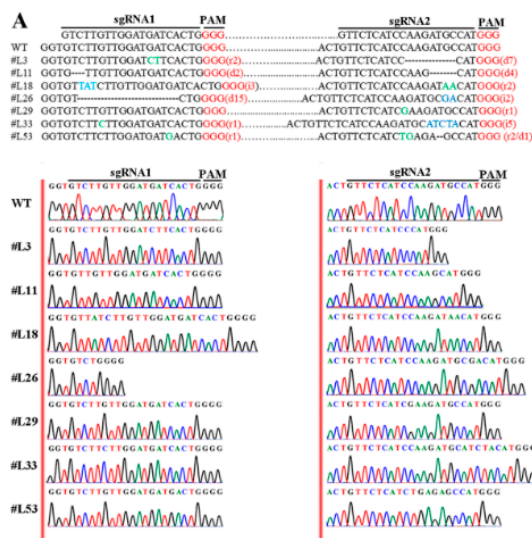

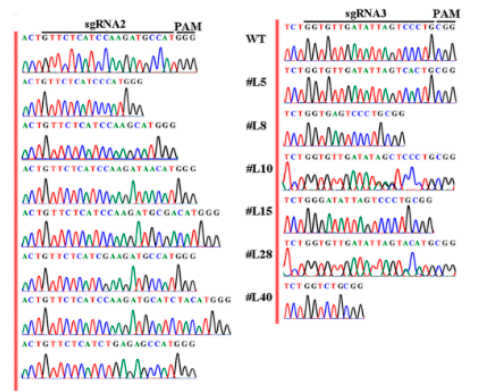

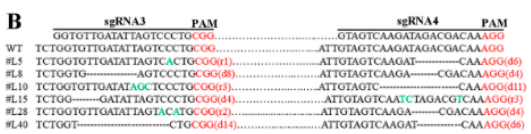

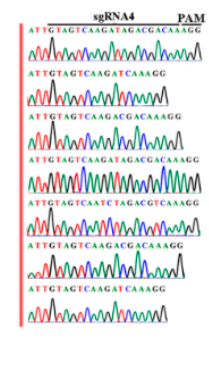

Figure 7. Identification of the mutation modes of KO-LpABCB21 (A) and KO-LpPILS7 (B) mutant lines. $\mathrm{r} / \mathrm{blue}$ indicate replacements. $\mathrm{i} / \mathrm{green}$ indicate insertions. $\mathrm{d} /$ - indicate deletions. Dots represent sequences between dual sgRNA. PAM represents NGG domains. 
Analysis of the changes in the protein sequences after mutations indicated that the protein sequences of KO-LpABCB21 and KO-LpPILS7 mutant lines had frame shift mutations, protein mutations between dual sgRNA, and amino acid mutations in dual sgRNA (Figure $8 C, F$ ). Three lines had amino acid mutations in dual sgRNA. KO-LpABCB21 line L18 had insertion of a nonpolar leucine (+L) and replacement of polar asparagine with nonpolar alanine $(\mathrm{N} \rightarrow \mathrm{A})$, and line $\mathrm{L} 29$ had replacement of polar negatively charged glutamate with polar glutamine $(\mathrm{E} \rightarrow \mathrm{Q})$. KO-LpPILS7 mutant line L5 had replacement of polar threonine with nonpolar proline $(\mathrm{T} \rightarrow \mathrm{P})$, and two polar negatively charged aspartic acid residues (-DD) were missing.
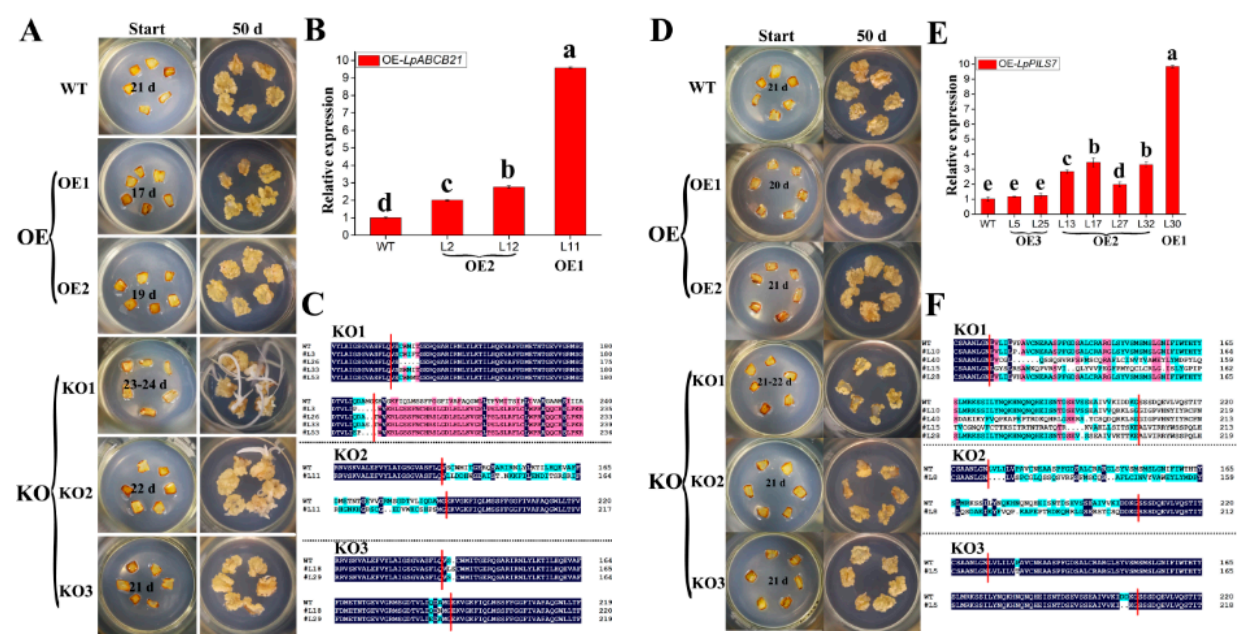

Figure 8. The effects of overexpression and knockout of LpABCB21 and LpPILS7 on somatic embryo induction in L. pumilum. (A), somatic embryo was induced by LpABCB21 transgenic lines; (B), the expression levels of $\angle p A B C B 21$ in overexpression lines; (C), the protein sequence alignment of KO-LpABCB21 mutant lines; (D), somatic embryo was induced by LPPILS7 transgenic lines; (E), the expression levels of LpPILS7 in overexpression lines; $(\mathbf{F})$, the protein sequence alignment of KO-LPPILS7 mutant lines. WT, wild-type plants; OE, overexpression lines; OE1, the expression level increases by more than 9-fold; OE2, the expression levels increases by 2-4-fold; OE3, the expression level did not change significantly; $\mathrm{KO}$, mutant lines; $\mathrm{KO} 1$, frame shift mutations; $\mathrm{KO}$ 2, mutation between dual sgRNA; KO3, mutations in dual sgRNA. Start, the emergence time of somatic embryo is marked in the image; $50 \mathrm{~d}$, somatic embryo induction for 50 days. Data were analyzed using one-way ANOVA using SPSS; the differences were compared using Fisher's least significant difference test (LSD) at the $5 \%$ significance level. The red vertical bars in $C$ and $F$ represent the edge of dual sgRNA.

Since $L p A B C B 21$ and LPPILS7 are membrane transporters, the hydrophilicity, hydrophobicity, and transmembrane domains of the mutant protein sequences were estimated by prediction. The results showed that hydrophilicity and hydrophobicity of the proteins were considerably affected by the frame shift mutation and protein mutations between dual sgRNA (B-D, G-J); however, these properties were affected to a lesser extent by the amino acid mutation in dual sgRNA (E, F, K, and L) (Figure S1). The wild-type $L p A B C B 21$ protein sequence consists of 11 transmembrane domains (A). The frame shift mutation resulted in deletion of the third to eleventh transmembrane domains $(\mathrm{B}, \mathrm{C}, \mathrm{D}$, and $\mathrm{E})$. The protein mutation between dual sgRNA caused deletion of the third transmembrane domain; the distribution of amino acid residues to the inner and outer membrane prior to the missing transmembrane domain was also affected $(\mathrm{F})$. The transmembrane domain of the amino acid mutant with mutation in dual sgRNA was identical to that of the wild-type protein ( $G$ and $H)$. The wild-type LpPILS7 protein sequence consists of 10 transmembrane domains (I). The frame shift mutations resulted in deletion of the third to tenth transmembrane domains ( $\mathrm{K}$ and $\mathrm{M}$ ) or the fifth to tenth transmembrane domains ( $\mathrm{J}$ and $\mathrm{L}$ ). The protein mutation between dual sgRNA resulted in deletion of the fourth transmembrane domain $(\mathrm{N})$. The transmembrane domain of the amino acid mutant with mutation in dual sgRNA was identical to that of the wild-type protein (O) (Figure S2). 
The assay of the expression levels in the overexpression lines showed that the level of $L A A B C B 21$ was significantly increased by 2.0-9.6-fold in 3 OE- $L P A B C B 21$ lines compared with that in wild-type plants (Figure 8B). In 7 OE-LpPILS7 lines, the expression level of LpPILS7 was significantly increased by 2.0-9.8-fold compared with that in wild-type plants except lines L5 and L25 (Figure 8E).

\subsection{Analysis of Genetic Transformation Efficiency}

As shown in Table 2, the RC5.0 and Germination II conditions (after improvement) are better than RC5.8 and Germination I conditions (before improvement); the germination rate increased by 17.7-42.1\%, the number of resistant plants increased by $2.7-6.4-$ fold, the number of positive lines increased by 3-6-fold, and the genetic transformation efficiency increased by $5.7-13.0 \%$.

Table 2. Comparison of genetic transformation efficiency before and after the improvement.

\begin{tabular}{ccccccc}
\hline Method. & Type & $\begin{array}{c}\text { Resistant } \\
\text { Calli }\end{array}$ & $\begin{array}{c}\text { Resistant } \\
\text { Plants }\end{array}$ & $\begin{array}{c}\text { Positive } \\
\text { Plants }\end{array}$ & $\begin{array}{c}\text { Germination } \\
\text { Rate }\end{array}$ & $\begin{array}{c}\text { Transformation } \\
\text { Efficiency }\end{array}$ \\
\hline \multirow{5}{*}{ Before } & OE-LpABCB21 & 13 & 5 & 0 & $38.5 \%$ & 0 \\
& KO-LpABCB21 & 21 & 15 & 5 & $71.4 \%$ & $33.3 \%$ \\
& OE-LpPILS7 & 35 & 7 & 1 & $20.0 \%$ & $14.3 \%$ \\
& KO-LpPILS7 & 31 & 11 & 4 & $35.5 \%$ & $36.4 \%$ \\
& OE-LpABCB21 & 42 & 32 & 3 & $76.2 \%$ & $9.4 \%$ \\
After & KO-LpABCB21 & 46 & 41 & 19 & $89.1 \%$ & $46.3 \%$ \\
& OE-LpPILS7 & 59 & 30 & 6 & $50.8 \%$ & $20.0 \%$ \\
& KO-LpPILS7 & 67 & 52 & 24 & $77.6 \%$ & $46.2 \%$ \\
\hline
\end{tabular}

\subsection{The Effects of LpABCB21 and LpABILS7 on SE}

The somatic embryo was formed when the scales of the wild-type plants were cultured in somatic embryo induction medium for 21 days, and the somatic embryo induction rate was $100 \%$. Comparison with somatic embryo induction in the wild-type plants indicated that $L p A B C B 21$ mainly regulated early SE and had a certain influence on regulation of late SE. After overexpression of $L p A B C B 21$, the emergence time of somatic embryos was advanced by 2-4 days. When the expression level increased by 2.0-2.8-fold, the somatic embryo induction efficiency was not changed. Although the expression levels in line L2 and L12 were significantly different, there were no differences in SE. When the expression level was significantly increased in line L11, somatic embryo induction efficiency decreased by approximately $30-40 \%$, and the emergence time of somatic embryos was advanced by additional 2 days compared with that in line L2 and L12. LPABCB21 mutation delayed the emergence time of somatic embryos by 1-3 days, and adventitious buds were formed in the late stage. The number of adventitious buds formed by the frame shift mutant (KO1) was the highest, and the adventitious bud induction rate was 79.2\% (19/24) (Figure 8A). LPPILS7 mainly regulated late SE and had little effect on early SE. Only a few lines can advance (OE1: L30) or delay (KO1: L10 and L40) the emergence of somatic embryos by 1 day. Somatic embryo induction efficiency increased by approximately $10-30 \%$ when LpPILS7 expression levels increased by 2.0-9.8-fold, while LpPILS7 mutations decreased somatic embryo induction efficiency by approximately $10-60 \%$ (Figure $8 \mathrm{D}$ ). Although there were transgenic lines with significantly different expression levels in OE2, there were no significant differences in SE. If the expression level was significant increased by 9.8 -fold (OE1), somatic embryo induction efficiency was further increased. The results of somatic embryo induction in various protein mutation modes indicated that proteins with the frame shift mutation (KO1) or the large fragment mutation $(\mathrm{KO} 2)$ had severely damaged function of the protein; however, the insertion, replacement, and deletion of individual amino acids (KO3) had weaker effect on the function of the protein. For example, $L p A B C B 21$ mutant lines L18 and L29 had almost no effect on SE. The somatic embryo induction efficiency of LpPILS7 mutant line L5 was reduced by 10\%, which was less than the effect of the $\mathrm{KO} 1$ and $\mathrm{KO} 2$ mutant lines. 


\section{Discussion}

The $\mathrm{pH}$ of the medium was reported to be crucial for Agrobacterium virulence in in vitro tissue culture [41]. The optimal $\mathrm{pH}$ for Agrobacterium growth is 7.0 [42], but optimal infection of the host occurs at $\mathrm{pH} 4.8-5.5$ [43,44]. In the presence of AS (acetosyringone), the induction of the vir gene is favored under the acidic conditions [32], while the expression of the vir gene is barely induced at neutral $\mathrm{pH}$; the expression level of the vir gene is increased by 1.2-2.0-fold when $\mathrm{pH}$ drops from 7.0 to 5.5 [43]. In the co-culture of Agrobacterium tumefaciens and plant cells, the expression level of the vir gene changes depending on $\mathrm{pH}$ and reaches the maximum at $\mathrm{pH} 5.1$ [43]; the expression level of the vir gene decreases when $\mathrm{pH}$ increases from 5.1 to 5.6 [41]. Genetic transformation efficiency is maximal when $\mathrm{pH}$ of the pre-culture or co-culture media is $5.0[25,45]$. The co-culture medium with pH 5.2 is more suitable for the genetic transformation of tomato (Solanum lycopersicum) cotyledon [46]. Our study further confirms that low $\mathrm{pH}$ can promote Agrobacterium-mediated genetic transformation. The number of resistant calli increased when $\mathrm{pH}$ of the re-suspension solution and co-culture medium decreased from 5.8 to 5.0 indicating that $\mathrm{pH} 5.0$ is more suitable for the genetic transformation of L. pumilum than $\mathrm{pH}$ 5.8. However, a pronounced decrease in $\mathrm{pH}$ has an inhibitory effect on genetic transformation [35]. Since the genetic transformation efficiency of L. pumilum was compared only under the conditions with $\mathrm{pH} 5.0$ and $\mathrm{pH} 5.8$ in this experiment, additional improvement in the genetic transformation efficiency of Lilium should consider optimization of $\mathrm{pH}$ of the transformation process.

Calcium ions are the major second messenger in plants, and the calcium signaling pathway has been extensively studied $[47,48]$. Recent studies have shown that $\mathrm{CaCl}_{2}$ (calcium chloride) can promote the induction of embryogenic calli (EC) and the germination of somatic embryos. Addition of $10 \mathrm{mM} \mathrm{CaCl}_{2}$ increased the germination rate of somatic embryos by $51.79 \%$ [49]. The results of the present study indicate that an increase in the content of $\mathrm{CaCl}_{2}$ from $0.44 \mathrm{~g} / \mathrm{L}$ to $1.32 \mathrm{~g} / \mathrm{L}$ can improve the germination coefficient of somatic embryos. However, the role of $\mathrm{CaCl}_{2}$ in $\mathrm{SE}$ is genotype- and variety-dependent [49]. Therefore, additional screening of optimal dosages is necessary for various materials, and the mechanism of $\mathrm{CaCl}_{2}$ regulation of the germination of somatic embryo requires additional investigation.

Previous studies have shown that $\mathrm{ABCB} 21$ and $\mathrm{ABCB} 4$ are bidirectional auxin transport carriers, which control the direction of auxin transport depending on auxin concentration to regulate the auxin level in the cells $[14,16]$. Recent studies in Arabidopsis have shown that ABCB21 can regulate the transport of auxin in cotyledons, root pericycle, and leaves to regulate normal growth [6]; however, the mechanism of SE regulation by ABCB21 remains unclear. ABCB21 has auxin influx or efflux activities under certain conditions, which is very similar to the pattern observed in $A B C B 4$ [17]. A recent study has shown that ABCB21 initially has auxin uptake activity until intracellular auxin concentration reaches a certain threshold; then, the efflux activity is activated [6]. Our data indicate that various expression levels of $L P A B C B 21$ may also influence auxin transport rate. Several studies have shown that SE is more easily induced when the explants contain high auxin levels [50-52], which indirectly indicates that the auxin content in the explants reaches a high level in advance may promote earlier formation of somatic embryos. However, the ratio of auxin to cytokinin determines the development fate of the reproductive organs [53]. These considerations suggest that the content of exogenous auxin or cytokinin entering the explants and the content of endogenous cytokinin and auxin in the explants should be assessed when the exogenous hormone is used to change the original development state of the explants so that the ratio of auxin to cytokinin is always within the threshold range required for specific organ development. In this study, when exogenous auxin was constant, somatic embryos appeared earlier in the overexpression lines indicating that auxin content may increase to a higher level within a certain period of time to reach the auxin threshold required for SE to advance. An increase in the expression of $L P A B C B 21$ may shorten the time required for auxin to reach the threshold of SE to induce an additional advance in the emergence time of somatic embryo. However, if the auxin content is so high that it exceeded a certain threshold, the continued growth of somatic embryo is inhibited. Bielach found that cytokinin application on lateral root primordia delays the appearance of 
maximum auxin levels and lateral root growth but has no effect on the formation of the lateral root [54]. ABCB21 mutations and cytokinin treatment produce the same results [6]. These studies confirm the results of our experiments. The emergence time of somatic embryos was delayed in the $L P A B C B 21$ mutant lines, and there was no significant influence on the induction efficiency of somatic embryos. It is not clear whether this is the result of functionally redundancy of ABCB4 with ABCB21 during SE or if $\mathrm{AUX} / \mathrm{LAX} 1$ and $\mathrm{ABCB} 21$ coordinate to regulate the exogenous auxin influx.

The function of PILS proteins in plant development is unclear; it is currently believed that PILS proteins can limit the rate of auxin signal transduction and response to external stimuli, such as light and temperature, to regulate auxin-dependent development $[8,22]$. Our results indicate that the mechanisms of LPPILS7 and LPABCB21 involved in auxin regulation may be similar; however, the proteins are associated with different patterns of auxin regulation. The reasons for this difference may be due to two factors. First, PILS protein is located at the ER and controls the accumulation of auxin in the cells. Second, the function of PILS protein mainly involves regulation of auxin signal through binding or releasing auxin and availability of auxin in the nucleus [8,22]; however, ABCB21 is located on the PM and is mainly involved in the balance of extracellular and intracellular levels of auxin. ABCB21 acts by determining the direction of auxin transport based on auxin concentration $[14,17]$. However, the ultimate result is the same. In in vitro tissue culture, the balance between exogenous and endogenous auxin levels can be adjusted so that the ratio between auxin and cytokinin can be maintained within the threshold range of specific requirements of a developmental process. When LPPILS7-overexpressimg and mutant lines induce somatic embryos, the effect on the emergence time of somatic embryos was very small. This phenomenon may be explained by very high rate of auxin transport [6]; hence, the process of exogenous hormone transport into the cells, which is probably determined by $L p A B C B 21$, is not affected. Our previous study demonstrated that LPPILS7 expression level is increased in the light culture, and somatic embryo induction efficiency in the light culture is better than that in the dark culture [40]. This experiment confirms that LPPILS7 can promote L. pumilum SE. PILS protein was suggested to bind auxin to limit nucleus auxin signaling [8,22]. PILS6 mutants have an increased auxin signal in the nucleus [8]. The results of this experiment suggest that PILS7 and PILS6 may have the same molecular mechanism of in regulation of auxin signals, which will be verified in the future studies.

In conclusion, this study describes a more efficient method of genetic transformation of L. pumilum improved by decreasing the $\mathrm{pH}$ of re-suspension solution and co-culture medium to 5.0 and increasing the $\mathrm{CaCl}_{2}$ concentration of germination medium to $1.32 \mathrm{~g} / \mathrm{L}$; these results are important for subsequent functional genomics studies and molecular breeding in Lilium. Our findings confirm that $L P A B C B 21$ and LpPILS7 have important regulatory roles in L. pumilum SE and contribute to determination of the molecular mechanism of Lilium SE.

\section{Materials and Methods}

\subsection{Plant Materials, Strains, and Vectors}

L. pumilum EC were used as material. EC were obtained according to a previously described method [55]. Cultures were grown at $25 \pm 1{ }^{\circ} \mathrm{C}$ under a $16 / 8 \mathrm{~h}$ photoperiod with a photosynthetic photon flux density of $36 \mu \mathrm{mol} \mathrm{m}{ }^{-2} \mathrm{~s}^{-1}$ provided by cool white fluorescent light bulbs (Philips, Shanghai, China).

Plant overexpression vector pRI101-ON was purchased from Takara Biomedical Technology Co., Ltd. (Dalian, China). Agrobacterium tumefaciens EHA105 harboring the helper plasmid pVS1-SAH2, CRISPR/Cas9 knockout vector pG3H-U3Ub, and template pCBC-DT1T2.2 were donated by Professor Chen Qijun from China Agricultural University. 


\subsection{Construction of Overexpression and CRISPR/Cas9 Knockout Vectors}

Primers with restriction enzyme cutting sites were designed using the Primer 5 software according to the sequences of the target genes and overexpression vectors. The sgRNA was designed according to the PAM/NGG domain on the sequences of the target genes. The sgRNA requires the content of GC $\%$ to be higher than $40 \%$, absence of four consecutive thymines, and continuous pairing between sgRNA and target gene less than $8 \mathrm{bp}$. The primers for overexpression and knockout vector construction are listed in Table S1.

Previously, sequencing verified plasmids of $L p A B C B 21$ and LpPILS7 were used as templates to clone the CDS of $L p A B C B 21$ and $L p P I L S 7$. The reaction system volume was $50 \mu \mathrm{L}$ containing $1 \mu \mathrm{L}$ of the LpABCB21/LpPILS7 plasmids, $1 \mu \mathrm{L}$ of LpABCB21-F/LpPILS7-F $(10 \mu \mathrm{M}), 1 \mu \mathrm{L}$ of LpABCB21-R/LpPILS7-R $(10 \mu \mathrm{M}), 22 \mu \mathrm{L}$ of $\mathrm{ddH}_{2} \mathrm{O}$, and $25 \mu \mathrm{L}$ of PrimeSTAR Max DNA polymerase (Takara, Dalian, China). The incubation was at $98^{\circ} \mathrm{C}$ for $1 \mathrm{~min}$; $\left(98^{\circ} \mathrm{C} 10 \mathrm{sec}\right.$, $60^{\circ} \mathrm{C} 5 \mathrm{sec}$., and $\left.72{ }^{\circ} \mathrm{C} 1 \mathrm{~min}\right) \times 30$ cycles; and $72{ }^{\circ} \mathrm{C}$ for $1 \mathrm{~min}$. The pBCB-MT1T2.2 plasmid was used as a template to clone the sgRNA expression cassettes. The reaction system volume was $50 \mu \mathrm{L}$ containing $1 \mu \mathrm{L}$ of the pBCB-MT1T2.2 plasmids; $1 \mu \mathrm{L}$ of $L p A B C B 21-\mathrm{BsF} / L p P I L S 7-\mathrm{BsF}(10 \mu \mathrm{M}) ; 1 \mu \mathrm{L}$ of LpABCB21-BsR/LpPILS7-BsR $(10 \mu \mathrm{M}) ; 1 \mu \mathrm{L}$ of LpABCB21-F0/LpPILS7-F0 $(1 \mu \mathrm{M}) ; 1 \mu \mathrm{L}$ of LpABCB21-R0/ LpPILS7-R0 $(1 \mu \mathrm{M}) ; 20 \mu \mathrm{L}$ of ddH $\mathrm{d}_{2}$; and $25 \mu \mathrm{L}$ of PrimeSTAR Max DNA polymerase. The incubation was at $98^{\circ} \mathrm{C}$ for $1 \mathrm{~min}$; $\left(98^{\circ} \mathrm{C} 10 \mathrm{~s}, 60{ }^{\circ} \mathrm{C} 5 \mathrm{~s}\right.$, and $\left.72{ }^{\circ} \mathrm{C} 30 \mathrm{~s}\right) \times 30$ cycles; and $72{ }^{\circ} \mathrm{C}$ for $1 \mathrm{~min}$. After the PCR product was purified, the CDS of the target genes and the sgRNA expression cassettes were inserted into pRI101-ON and pG3H-U3Ub, respectively, by enzymatic ligation.

\subsection{Improvement of Agrobacterium-Mediated Genetic Transformation System}

The genetic transformation method was performed as described previously [40]. In brief, EC were transferred to somatic embryo induction medium for proliferation and subcultured every 30 days until genetic transformation was performed. Light yellowish friable EC were selected as recipient materials. Agrobacterium expressing the vectors was grown in a liquid medium until the $\mathrm{OD}_{600}$ value reached 0.6. Collected bacteria were subjected to Re-suspension I in the same volume to suspend the bacteria. After addition of $100 \mu \mathrm{mol}$ AS, the EC that had been precultured in the pre-cultivation medium for 10 days were infected for $15 \mathrm{~min}$. The EC were inoculated into Co-cultivation I for culture for 3 days in the dark, and then inoculated into Selection I and Selection II media for 2 weeks. Finally, transformed EC were inoculated into Germination I for germination. The results of preliminary experiments (Supplementary Table R1 and Figure R1) demonstrated that the germination efficiency of somatic embryos was the highest when non-transformed EC were inoculated in Germination II in the light culture (the light period was 16/8 h). To further improve the genetic transformation efficiency, the following aspects were improved. The original method was used as the control. The media used in the transformation process are shown in Appendix A Table A1.

Improvement of culture condition: The $\mathrm{pH}$ of the re-suspended solution and co-culture medium were changed to 5.0. The number of resistant calli was counted.

Improvement of somatic embryo germination condition: EC were inoculated into Germination II for germination. Statistics of somatic embryo germination efficiency was assessed.

\subsection{Identification of LpABCB21 and LPPILS7 Transgenic Plants}

The genomic DNA of the leaves was extracted and used as a template for PCR identification. The primers for identification of transgenic plants are listed in Table S2. Specific primers for identification of overexpression in plants were designed based on the 35S promoter sequence (35S-F), the inserted DNA fragments (B21-R and S7-R), and the NPT II sequence (NTP II-F and NTP II-R). The expression levels in the overexpression plants were detected according to the previously described method [40]. Specific primers for identification of knockout plants were designed based on the OsU3 and TaU3 promoter (OsU3p and TaU3p) [56]. Specific primers for identification of the mutation mode were 
designed outside of the dual sgRNA (s7-F, s7-R, b21-F, and b21-R). DNAMAN software (version 7.0.2) was used to analyze the hydrophilicity and hydrophobicity. TMHMM (TransMembrane prediction using Hidden Markov Models) software (http://www.cbs.dtu.dk/services/TMHMM/) was used to analyze the transmembrane domains.

\subsection{Identification of the Function of LpABCB21 and LpABILS7 in SE}

The scales of the overexpression lines and mutant lines were used as explants. The scales were cut into small pieces of approximately $0.5 \mathrm{~cm}^{2}$ and inoculated in the somatic embryo induction medium for dark culture. The wild-type plants were used as the control. The emergence time of somatic embryos was estimated. The results of somatic embryo induction were assessed after culture for 50 days.

Supplementary Materials: Supplementary materials can be found at http://www.mdpi.com/1422-0067/21/18/ 6784/s1.

Author Contributions: Conceptualization S.S. and H.S.; Formal analysis, S.S., C.W. and J.W.; Investigation, S.S.; Methodology, S.S.; Resources, S.S. and R.Y.; Software, S.S.; Supervision, H.S.; Visualization, S.S.; Writing一original draft, S.S.; Writing-review \& editing, S.S., R.Y., C.W., J.W. and H.S. All authors have read and agreed to the published version of the manuscript.

Funding: This work was supported by the National Natural Science Foundation of China (grant numbers 31872150 and 31672179) and the National Key Research and Development Program of China (2018YFD1000407).

Acknowledgments: We thank Chen Qijun (China Agricultural University, China) for providing plasmids pG3H-U3Ub and template pCBC-DT1T2.2, and we thank Wang Zhiping (Shenyang Agricultural University, China) for designing sgRNA.

Conflicts of Interest: The authors declare no conflict of interest.

\section{Abbreviations}

MS (Culture medium)

PIC (IAA analogue)

NAA (Auxin analogue)

6-BA (Cytokinin)

AS (Chemical material)

Cef (Antibiotic)

Hyg (Antibiotic)

Kan (Antibiotic)

Rif (Antibiotic)

\section{Murashige-Skoog}

Picloram (Sigma-Aldrich, United States)

1-Naphthaleneacetic acid (Sigma-Aldrich, United States)

6-Benzylaminopurine (Tiangen, Beijing, China)

Acetosyringone (Tiangen, Beijing, China)

Cefotaxime (Tiangen, Beijing, China)

Hygromycin (Sigma-Aldrich, United States)

Kanamycin (Tiangen, Beijing, China)

Rifampicin (Tiangen, Beijing, China)

\section{Appendix A}

Table A1. Genetic transformation medium for Lilium pumilum DC. Fisch.

\begin{tabular}{|c|c|}
\hline Media & Composition \\
\hline Pre-cultivation/somatic embryo induction & $\begin{array}{c}\text { MS (Murashige-Skoog) }+1.0 \mathrm{mg} / \mathrm{L} \mathrm{PIC} \mathrm{(Picloram)}+0.2 \mathrm{mg} / \mathrm{L} \\
\text { NAA (1-Naphthaleneacetic acid) }+30 \mathrm{~g} / \mathrm{L} \text { Sucrose }+7 \mathrm{~g} / \mathrm{L} \text { Agar } \mathrm{PH}=5.8\end{array}$ \\
\hline Re-suspension I & $1 / 2 \mathrm{MS}\left(\mathrm{NH}_{4} \mathrm{NO}_{3}\right.$-free) $+60 \mathrm{~g} / \mathrm{L}$ Sucrose $+100 \mu \mathrm{mol}$ AS (Acetosyringone); $\mathrm{pH}=5.8$ \\
\hline Re-suspension II & $1 / 2 \mathrm{MS}\left(\mathrm{NH}_{4} \mathrm{NO}_{3}\right.$-free $)+60 \mathrm{~g} / \mathrm{L}$ Sucrose $+100 \mu \mathrm{mol} \mathrm{AS} ; \mathrm{pH}=5.0$ \\
\hline Co-cultivation I & $\begin{array}{c}\mathrm{MS}\left(\mathrm{NH}_{4} \mathrm{NO}_{3} \text {-free }\right)+1.0 \mathrm{mg} / \mathrm{L} \mathrm{PIC}+0.2 \mathrm{mg} / \mathrm{L} \mathrm{NAA}+100 \mu \mathrm{mol} \mathrm{AS}+60 \mathrm{~g} / \mathrm{L} \text { Sucrose }+ \\
7 \mathrm{~g} / \mathrm{L} \text { Agar; } \mathrm{PH}=5.8\end{array}$ \\
\hline Co-cultivation II & $\begin{array}{c}\mathrm{MS}\left(\mathrm{NH}_{4} \mathrm{NO}_{3} \text {-free }\right)+1.0 \mathrm{mg} / \mathrm{L} \mathrm{PIC}+0.2 \mathrm{mg} / \mathrm{L} \mathrm{NAA}+100 \mu \mathrm{mol} \mathrm{AS}+60 \mathrm{~g} / \mathrm{L} \text { Sucrose }+ \\
7 \mathrm{~g} / \mathrm{L} \text { Agar; } \mathrm{pH}=5.0\end{array}$ \\
\hline Selection I & $\begin{array}{c}\mathrm{MS}\left(\mathrm{NH}_{4} \mathrm{NO}_{3} \text {-free }\right)+1.0 \mathrm{mg} / \mathrm{L} \mathrm{PIC}+0.2 \mathrm{mg} / \mathrm{L} \mathrm{NAA}+30 \mathrm{~g} / \mathrm{L} \text { Sucrose }+7 \mathrm{~g} / \mathrm{L} \text { Agar }+ \\
400 \mathrm{mg} / \mathrm{L} \mathrm{Cef} \mathrm{(Cefotaxime)+50} \mathrm{mg/L} \mathrm{Kan} \mathrm{(Kanamycin);} \mathrm{pH}=5.8 \text { (Overexpression) } \\
\mathrm{MS}\left(\mathrm{NH}_{4} \mathrm{NO}_{3} \text {-free) }+1.0 \mathrm{mg} / \mathrm{L} \mathrm{PIC}+0.2 \mathrm{mg} / \mathrm{L} \mathrm{NAA}+30 \mathrm{~g} / \mathrm{L} \text { Sucrose }+7 \mathrm{~g} / \mathrm{L} \text { Agar }+\right. \\
400 \mathrm{mg} / \mathrm{L} \mathrm{Cef}+30 \mathrm{mg} / \mathrm{L} \mathrm{Hyg} \text { (Hygromycin); } \mathrm{pH}=5.8 \text { (Knockout) }\end{array}$ \\
\hline Selection II & $\begin{array}{c}\mathrm{MS}\left(\mathrm{NH}_{4} \mathrm{NO}_{3}-\text { free }\right)+1.0 \mathrm{mg} / \mathrm{L} \mathrm{PIC}+0.2 \mathrm{mg} / \mathrm{L} \mathrm{NAA}+30 \mathrm{~g} / \mathrm{L} \text { Sucrose }+7 \mathrm{~g} / \mathrm{L} \text { Agar }+ \\
400 \mathrm{mg} / \mathrm{L} \mathrm{Cef}+25 \mathrm{mg} / \mathrm{L} \mathrm{Kan} ; \mathrm{pH}=5.8 \text { (Overexpression) } \\
\mathrm{MS}\left(\mathrm{NH}_{4} \mathrm{NO}_{3} \text {-free }\right)+1.0 \mathrm{mg} / \mathrm{L} \mathrm{PIC}+0.2 \mathrm{mg} / \mathrm{L} \mathrm{NAA}+30 \mathrm{~g} / \mathrm{L} \text { Sucrose }+7 \mathrm{~g} / \mathrm{L} \mathrm{Agar}+ \\
400 \mathrm{mg} / \mathrm{L} \mathrm{Cef}+15 \mathrm{mg} / \mathrm{L} \mathrm{Hyg} ; \mathrm{pH}=5.8 \text { (Knockout) }\end{array}$ \\
\hline Germination I & $\mathrm{MS}+0.5 \mathrm{mg} / \mathrm{L}$ 6-BA (6-Benzylaminopurine) $+30 \mathrm{~g} / \mathrm{L}$ Sucrose $+7 \mathrm{~g} / \mathrm{L}$ Agar; $\mathrm{pH}=5.8$ \\
\hline Germination II & $\begin{array}{c}\mathrm{MS}+0.5 \mathrm{mg} / \mathrm{L} 6-\mathrm{BA}+0.88 \mathrm{~g} / \mathrm{L} \mathrm{CaCl} 2(\text { calcium chloride })+30 \mathrm{~g} / \mathrm{L} \text { Sucrose }+7 \mathrm{~g} / \mathrm{L} \text { Agar; } \\
\mathrm{pH}=5.8\end{array}$ \\
\hline
\end{tabular}




\section{References}

1. Zou, M.; Ren, H.; Li, J. An Auxin Transport Inhibitor Targets Villin-Mediated Actin Dynamics to Regulate Polar Auxin Transport. Plant Physiol. 2019, 181, 161-178. [CrossRef] [PubMed]

2. Schnabel, E.L.; Frugoli, J. The PIN and LAX families of auxin transport genes in Medicago truncatula. Mol. Genet. Genom. MGG 2004, 272, 420-432. [CrossRef]

3. Zhang, Y.; He, P.; Yang, Z.; Huang, G.; Wang, L.; Pang, C.; Xiao, H.; Zhao, P.; Yu, J.; Xiao, G. A Genome-Scale Analysis of the PIN Gene Family Reveals Its Functions in Cotton Fiber Development. Front. Plant Sci. 2017, 8, 461. [CrossRef] [PubMed]

4. Zhang, Y.; Hartinger, C.; Wang, X.; Friml, J. Directional auxin fluxes in plants by intramolecular domain-domain coevolution of PIN auxin transporters. New Phytol. 2020, 227, 1406-1416. [CrossRef] [PubMed]

5. Swarup, R.; Peret, B. AUX/LAX family of auxin influx carriers-an overview. Front. Plant Sci. 2012, 3, 225. [CrossRef]

6. Jenness, M.K.; Carraro, N.; Pritchard, C.A.; Murphy, A.S. The Arabidopsis ATP-BINDING CASSETTE Transporter ABCB21 Regulates Auxin Levels in Cotyledons, the Root Pericycle, and Leaves. Front. Plant Sci. 2019, 10, 806. [CrossRef]

7. Barbez, E.; Kubes, M.; Rolcik, J.; Beziat, C.; Pencik, A.; Wang, B.; Rosquete, M.R.; Zhu, J.; Dobrev, P.I.; Lee, Y.; et al. A novel putative auxin carrier family regulates intracellular auxin homeostasis in plants. Nature 2012, 485, 119-122. [CrossRef]

8. Feraru, E.; Feraru, M.I.; Barbez, E.; Waidmann, S.; Sun, L.; Gaidora, A.; Kleine-Vehn, J. PILS6 is a temperature-sensitive regulator of nuclear auxin input and organ growth in Arabidopsis thaliana. Proc. Natl. Acad. Sci. USA 2019, 116, 3893-3898. [CrossRef]

9. Xu, Y.X.; Liu, Y.; Chen, S.T.; Li, X.Q.; Xu, L.G.; Qi, Y.H.; Jiang, D.A.; Jin, S.H. The B subfamily of plant ATP binding cassette transporters and their roles in auxin transport. Biol. Plant. 2014, 58, 401-410. [CrossRef]

10. Geisler, M.; Aryal, B.; di Donato, M.; Hao, P. A Critical View on ABC Transporters and Their Interacting Partners in Auxin Transport. Plant Cell Physiol. 2017, 58, 1601-1614. [CrossRef]

11. Cho, M.; Cho, H.T. The function of ABCB transporters in auxin transport. Plant Signal. Behav. 2013, 8, e22990. [CrossRef] [PubMed]

12. Borghi, L.; Kang, J.; de Brito Francisco, R. Filling the Gap: Functional Clustering of ABC Proteins for the Investigation of Hormonal Transport in planta. Front. Plant Sci. 2019, 10, 422. [CrossRef] [PubMed]

13. Bouchard, R.; Bailly, A.; Blakeslee, J.J.; Oehring, S.C.; Vincenzetti, V.; Lee, O.R.; Paponov, I.; Palme, K.; Mancuso, S.; Murphy, A.S.; et al. Immunophilin-like TWISTED DWARF1 modulates auxin efflux activities of Arabidopsis P-glycoproteins. J. Biol. Chem. 2006, 281, 30603-30612. [CrossRef] [PubMed]

14. Kamimoto, Y.; Terasaka, K.; Hamamoto, M.; Takanashi, K.; Fukuda, S.; Shitan, N.; Sugiyama, A.; Suzuki, H.; Shibata, D.; Wang, B.; et al. Arabidopsis ABCB21 is a facultative auxin importer/exporter regulated by cytoplasmic auxin concentration. Plant Cell Physiol. 2012, 53, 2090-2100. [CrossRef] [PubMed]

15. Bailly, A.; Yang, H.B.; Martinoia, E.; Geisler, M.; Murphy, A.S. Plant lessons: Exploring ABCB functionality through structural modeling. Front. Plant Sci. 2012, 2, 108. [CrossRef]

16. Kubes, M.; Yang, H.; Richter, G.L.; Cheng, Y.; Mlodzinska, E.; Wang, X.; Blakeslee, J.J.; Carraro, N.; Petrasek, J.; Zazimalova, E.; et al. The Arabidopsis concentration-dependent influx/efflux transporter ABCB4 regulates cellular auxin levels in the root epidermis. Plant J. Cell Mol. Biol. 2012, 69, 640-654. [CrossRef]

17. Yang, H.B.; Murphy, A.S. Functional expression and characterization of Arabidopsis ABCB, AUX 1 and PIN auxin transporters in Schizosaccharomyces pombe. Plant J. 2009, 59, 179-191. [CrossRef] [PubMed]

18. Swarup, R.; Bennett, M.J.T.B. Auxin transport: Providing plants with a new sense of direction. Biochemist 2014, 36, 12-15. [CrossRef]

19. Feraru, E.; Vosolsobe, S.; Feraru, M.I.; Petrasek, J.; Kleine-Vehn, J. Evolution and Structural Diversification of PILS Putative Auxin Carriers in Plants. Front. Plant Sci. 2012, 3, 227. [CrossRef]

20. Mravec, J.; Skupa, P.; Bailly, A.; Hoyerova, K.; Krecek, P.; Bielach, A.; Petrasek, J.; Zhang, J.; Gaykova, V.; Stierhof, Y.-D.; et al. Subcellular homeostasis of phytohormone auxin is mediated by the ER-localized PIN5 transporter. Nature 2009, 459, 1136-1140. [CrossRef]

21. Sauer, M.; Kleine-Vehn, J. PIN-FORMED and PIN-LIKES auxin transport facilitators. Development $2019,146$. [CrossRef] [PubMed] 
22. Beziat, C.; Barbez, E.; Feraru, M.I.; Lucyshyn, D.; Kleine-Vehn, J. Light triggers PILS-dependent reduction in nuclear auxin signalling for growth transition. Nat. Plants 2017, 3. [CrossRef] [PubMed]

23. Bennett, T.; Brockington, S.F.; Rothfels, C.; Graham, S.W.; Stevenson, D.; Kutchan, T.; Rolf, M.; Thomas, P.; Wong, G.K.; Leyser, O.; et al. Paralogous radiations of PIN proteins with multiple origins of noncanonical PIN structure. Mol. Biol. Evol. 2014, 31, 2042-2060. [CrossRef] [PubMed]

24. Sun, L.; Feraru, E.; Feraru, M.I.; Waidmann, S.; Wang, W.F.; Passaia, G.; Wang, Z.Y.; Wabnik, K.; Kleine-Vehn, J. PIN-LIKES Coordinate Brassinosteroid Signaling with Nuclear Auxin Input in Arabidopsis thaliana. Curr. Biol. 2020, 30, 1579-1588.e6. [CrossRef] [PubMed]

25. Rai, G.K.; Rai, N.P.; Kumar, S.; Yadav, A.; Rathaur, S.; Singh, M. Effects of explant age, germination medium, pre-culture parameters, inoculation medium, $\mathrm{pH}$, washing medium, and selection regime on Agrobacterium-mediated transformation of tomato. Vitr. Cell. Dev. Biol.-Plant 2012, 48, 565-578. [CrossRef]

26. Binns, A.N.; Zhao, J. The MexE/MexF/AmeC Efflux Pump of Agrobacterium tumefaciens and Its Role in Ti Plasmid Virulence Gene Expression. J. Bacteriol. 2020, 202. [CrossRef] [PubMed]

27. Lin, Y.H.; Pierce, B.D.; Fang, F.; Wise, A.; Binns, A.N.; Lynn, D.G. Role of the VirA histidine autokinase of Agrobacterium tumefaciens in the initial steps of pathogenesis. Front. Plant Sci. 2014, 5, 195. [CrossRef] [PubMed]

28. McCullen, C.A.; Binns, A.N. Agrobacterium tumefaciens and plant cell interactions and activities required for interkingdom macromolecular transfer. Annu. Rev. Cell Dev. Biol. 2006, 22, 101-127. [CrossRef] [PubMed]

29. Venturi, V.; Fuqua, C. Chemical signaling between plants and plant-pathogenic bacteria. Annu. Rev. Phytopathol. 2013, 51, 17-37. [CrossRef] [PubMed]

30. Brencic, A.; Winans, S.C. Detection of and response to signals involved in host-microbe interactions by plant-associated bacteria. Microbiol. Mol. Biol. Rev. MMBR 2005, 69, 155-194. [CrossRef]

31. Palmer, A.G.; Gao, R.; Maresh, J.; Erbil, W.K.; Lynn, D.G. Chemical biology of multi-host/pathogen interactions: Chemical perception and metabolic complementation. Annu. Rev. Phytopathol. 2004, 42, 439-464. [CrossRef]

32. Winans, S.C. Transcriptional induction of an Agrobacterium regulatory gene at tandem promoters by plant-released phenolic compounds, phosphate starvation, and acidic growth media. J. Bacteriol. 1990, 172, 2433-2438. [CrossRef] [PubMed]

33. Hiei, Y.; Ishida, Y.; Komari, T. Progess of cereal transformation technology mediated by Agrobacterium tumefaciens. Front. Plant Sci. 2014, 5, 628. [CrossRef] [PubMed]

34. Cohen, A.; Meredith, C.P. Agrobacterium-Mediated Transformation of Lilium; International Society for Horticultural Science (ISHS): Leuven, Belgium, 1992; pp. 611-618.

35. Ogaki, M.; Furuichi, Y.; Kuroda, K.; Chin, D.P.; Ogawa, Y.; Mii, M. Importance of co-cultivation medium pH for successful Agrobacterium-mediated transformation of Lilium x formolongi. Plant Cell Rep. 2008, 27, 699-705. [CrossRef] [PubMed]

36. Qi, Y.Y.; Du, L.J.; Quan, Y.H.; Tian, F.F.; Liu, Y.L.; Wang, Y.J. Agrobacterium-mediated transformation of embryogenic cell suspension cultures and plant regeneration in Lilium tenuifolium oriental $\mathrm{x}$ trumpet 'Robina'. Acta Physiol. Plant. 2014, 36, 2047-2057. [CrossRef]

37. Wei, C.; Cui, Q.; Lin, Y.; Jia, G.X. Efficient Agrobacterium-mediated transformation of Lilium Oriental 'Sorbonne' with genes encoding anthocyanin regulators. Can. J. Plant Sci. 2017. [CrossRef]

38. Abbasi, H.; Naderi, R.; Kafi, M.; Azadi, P.; Shakh-Asadi, M.; Okazaki, K. Effect of 'Chloroxynil' on Agrobacterium-mediated transformation efficiency of Lilium cv 'Manissa'. Sci. Hortic. 2020, 271. [CrossRef]

39. Yan, R.; Wang, Z.; Ren, Y.; Li, H.; Liu, N.; Sun, H. Establishment of Efficient Genetic Transformation Systems and Application of CRISPR/Cas9 Genome Editing Technology in Lilium pumilum DC. Fisch. and Lilium longiflorum White Heaven. Int. J. Mol. Sci. 2019, 20, 2920. [CrossRef] [PubMed]

40. Song, S.; Wang, Z.; Ren, Y.; Sun, H. Full-Length Transcriptome Analysis of the ABCB, PIN/PIN-LIKES, and AUX/LAX Families Involved in Somatic Embryogenesis of Lilium pumilum DC. Fisch. Int. J. Mol. Sci. 2020, 21, 453. [CrossRef]

41. Vernade, D.; Herrera-Estrella, A.; Wang, K.; Van Montagu, M. Glycine betaine allows enhanced induction of the Agrobacterium tumefaciens vir genes by acetosyringone at low pH. J. Bacteriol. 1988, 170, 5822-5829. [CrossRef]

42. Li, L.; Jia, Y.; Hou, Q.; Charles, T.C.; Nester, E.W.; Pan, S.Q. A global pH sensor: Agrobacterium sensor protein ChvG regulates acid-inducible genes on its two chromosomes and Ti plasmid. Proc. Natl. Acad. Sci. USA 2002, 99, 12369-12374. [CrossRef] [PubMed] 
43. Stachel, S.E.; Nester, E.W.; Zambryski, P.C. A plant cell factor induces Agrobacterium tumefaciens vir gene expression. Proc. Natl. Acad. Sci. USA 1986, 83, 379-383. [CrossRef] [PubMed]

44. Winans, S.C. Two-way chemical signaling in Agrobacterium-plant interactions. Microbiol. Rev. 1992, 56, 12-31. [CrossRef] [PubMed]

45. Wu, Y.F.; Chen, Y.; Liang, X.M.; Wang, X.Z. An Experimental Assessment of the Factors Influencing Agrobacterium-Mediated Transformation in Tomato. Fiziol. Rastenii 2006, 53, 280-284. [CrossRef]

46. Gao, N.; Shen, W.; Cao, Y.; Su, Y.; Shi, W. Influence of bacterial density during preculture on Agrobacterium-mediated transformation of tomato. Plant Cell Tissue Organ Cult. (PCTOC) 2009, 98, 321-330. [CrossRef]

47. Jaworski, K.; Pawełek, A.; Szmidt-Jaworska, A.; Kopcewicz, J. Expression of Calcium-Dependent Protein Kinase Gene (PnCDPK1) is Affected by Various Light Conditions in Pharbitis nil Seedlings. J. Plant Growth Regul. 2010, 29, 316-327. [CrossRef]

48. Jaworski, K.; Szmidt-Jaworska, A.; Kopcewicz, J. Two calcium dependent protein kinases are differently regulated by light and have different activity patterns during seedling growth in Pharbitis nil. Plant Growth Regul. 2011, 65, 369-379. [CrossRef]

49. Marimuthu, K.; Subbaraya, U.; Suthanthiram, B.; Marimuthu, S.S. Molecular analysis of somatic embryogenesis through proteomic approach and improvement of protocol in recalcitrant Musa spp. Physiol. Plant. 2019, 167, 282-301. [CrossRef]

50. Jimenez, V.M.; Guevara, E.; Herrera, J.; Bangerth, F. Evolution of endogenous hormone concentration in embryogenic cultures of carrot during early expression of somatic embryogenesis. Plant Cell Rep. 2005, 23, 567-572. [CrossRef]

51. Marquez-Lopez, R.E.; Perez-Hernandez, C.; Ku-Gonzalez, A.; Galaz-Avalos, R.M.; Loyola-Vargas, V.M. Localization and transport of indole-3-acetic acid during somatic embryogenesis in Coffea canephora. Protoplasma 2017, 255, 695-708. [CrossRef]

52. Pitschmann, A.; Purevsuren, S.; Obmann, A.; Natsagdorj, D.; Gunbilig, D.; Narantuya, S.; Kletter, C.; Glasl, S. Traditional Mongolian Medicine: History and status quo. Phytochem. Rev. 2013, 12, 943-959. [CrossRef]

53. Ikeuchi, M.; Ogawa, Y.; Iwase, A.; Sugimoto, K. Plant regeneration: Cellular origins and molecular mechanisms. Development 2016, 143, 1442-1451. [CrossRef] [PubMed]

54. Bielach, A.; Podlesakova, K.; Marhavy, P.; Duclercq, J.; Cuesta, C.; Muller, B.; Grunewald, W.; Tarkowski, P.; Benkova, E. Spatiotemporal regulation of lateral root organogenesis in Arabidopsis by cytokinin. Plant Cell 2012, 24, 3967-3981. [CrossRef]

55. Zhang, J.; Gai, M.; Li, X.; Li, T.; Sun, H. Somatic embryogenesis and direct as well as indirect organogenesis in Lilium pumilum DC. Fisch., an endangered ornamental and medicinal plant. Biosci. Biotechnol. Biochem. 2016, 80, 1898-1906. [CrossRef]

56. Zhang, Q.; Zhang, Y.; Lu, M.H.; Chai, Y.P.; Jiang, Y.Y.; Zhou, Y.; Wang, X.C.; Chen, Q.J. A Novel Ternary Vector System United with Morphogenic Genes Enhances CRISPR/Cas Delivery in Maize. Plant Physiol. 2019, 181, 1441-1448. [CrossRef]

(C) 2020 by the authors. Licensee MDPI, Basel, Switzerland. This article is an open access article distributed under the terms and conditions of the Creative Commons Attribution (CC BY) license (http://creativecommons.org/licenses/by/4.0/). 